\title{
Visual stimulus satiation as a function of duration of stimulus exposure and elapsed time following exposure
}

\author{
GARY W. R. PATTON \\ Indiana University of Pennsylvania, Indiana, Pa. 15701
}

The following hypotheses derived from Glanzer's (1953) theory of stimulus satiation effects were tested: (1) The longer $\mathbf{S}$ is exposed to a visual stimulus, the less likely he is to request a repetition of that stimulus, and (2) increasing the elapsed time following stimulus exposure increases the likelihood that $S$ will request a repetition of that stimulus. A 4 by 4 by 2 factorial design utilizing 64 undergraduate Ss of both sexes was used to test the hypotheses. A subsequent analysis of variance produced results confirming Hypothesis 1, but not Hypothesis 2.

In proposing a theory of stimulus satiation effects, Glanzer (1953) wrote, "Each moment an organism perceives a stimulus-object or stimulus-objects $A$, there develops a quantity of stimulus satiation to $\mathrm{A}$... Stimulus satiation reduces the organism's tendency to make any response to A ... As long as an organism remains perceiving $A$, the amount of stimulus satiation it has to $A$ at a given moment ... is an increasing negative exponential function of time ... When an organism stops perceiving $A$, the amount of stimulus satiation that it has to $\mathrm{A}$ at a given moment is a decreasing negative exponential function of time."

As noted by Cantor (1968), most experimental work with preschool and grade-school children has supported Glanzer's contention that exposure decreases interest in a stimulus, making it increasingly likely that a second stimulus will capture the child's attention. Other studies have tested specifically the effect on stimulus satiation of variations in (1) number of stimulus exposures (Cantor \& Cantor, 1964a, 1966) and length of stimulus exposures (Endsley, 1967; Endsley \& Kessel, 1969), and (2) the passage of time following exposure (Berlyne, 1957; Cantor \& Cantor, 1964a, b, 1966). The purpose of the present experiment was to extend the latter studies by using (1) shorter stimulus exposures, (2) shorter poststimulus delays, and (3) adults, as opposed to children, as Ss. From Glanzer's theory, the following hypotheses were drawn: (1) The longer $S$ is exposed to a picture, the more likely he is to select a new picture in preference to a reexposure of the present one; (2) if stimulus satiation decreases over time, then the longer the delay between the previous exposure and his decision, the more likely $S$ is to select the previously exposed picture.

\section{SUBJECTS}

The Ss were 32 female and 32 male undergraduate students conscripted from general psychology sections at Indiana University of Pennsylvania.

$$
\text { APPARATUS }
$$

The Ss were shown 10 colored slides selected by the E for aesthetic appeal and neutral content. Included were photographs of flowers, trees, buildings, and boats. A Kodak Ektographic Carousel slide projector displayed the slides on a $0.37-\mathrm{m}^{2}$ Radiant Imperial screen. Exposure duration was controlled by a Wollensak Alphax shutter. Time intervals between exposures and $S$ decisions were measured by a standard stopwatch.

\section{DESIGN}

Three independent variables, i.e., (1) exposure duration, (2) elapsed time following exposure, and (3) sex of $S$, were varied according to a 4 by 4 by 2 factorial design to determine their effects upon the dependent variable-number of times the previously seen slide was chosen in preference to a new one. The four exposure durations used were 0.10 , $0.20,1.00$, and $10.00 \mathrm{sec}$. These durations were not evenly spaced because pilot data indicated that most stimulus satiation would occur in less than 1 sec. The four delay periods between slide presentations and $\mathbf{S}$ decisions were $0.00,10.00,20.00$, and $30.00 \mathrm{sec}$. The third independent variable, sex of $S$, was included as a control to indicate whether or not the effects obtained were consistent between the sexes.

\section{PROCEDURE}

Except for the aforementioned variations in (1) duration of slide exposure and (2) elapsed time preceding $S$ 's decision, the procedure employed in all experimental conditions was nearly identical. Each $\mathbf{S}$ viewed the 10 slides one after another in the same order. After each exposure, $\boldsymbol{S}$ decided whether to see the previous slide again or request a new one. $S$ sat in a darkened room $1.52 \mathrm{~m}$ in front of a screen. The slide projector and the $\mathrm{E}$ operating it were behind and $0.61 \mathrm{~m}$ to the left of $\mathrm{S}$.

In the instructions $S$ was told that he was participating in a study of art appreciation and that for the next $20 \mathrm{~min}$ a series of art slides would be projected briefly on the screen in front of him. $S$ was informed that immediately after each slide exposure $E$ would call out a different three-digit number and that, upon hearing it, he should start counting slowly and steadily backward from that number until $E$ told him to stop. Then, immediately after E said "stop," he was to decide whether he wanted to see the previous slide again or a new one. S was assured that he could request as many or as few repetitions of a slide as he desired. Finally, $\mathbf{S}$ was told that the preceding procedure would be repeated until the $20 \mathrm{~min}$ had elapsed.

In all conditions, slide exposures were separated by $30 \mathrm{sec}$ to keep the sessions nearly equal in length. In the 30 -sec delay conditions, $S$ counted backward continuously for $30 \mathrm{sec}$ before making a decision. However, in the $10-$ and 20 -sec delay conditions, his count was interrupted by the decision, then resumed (from a new number) until the full $30 \mathrm{sec}$ elapsed. Finally, in the 0 -sec delay condition, the decision was made immediately after the exposure and was followed by a count lasting $30 \mathrm{sec}$.

Counting was used to lessen the possibility that Ss would make decisions regarding the slides before their assigned delay period had expired. Without this task, Ss would find it easier to decide immediately after seeing a slide, then keep this choice in mind until the assigned delay interval had elapsed. To produce a set in the $S s$ for the casual examination and enjoyment of the slides, they were led to believe that the experiment studied art appreciation. Finally, Ss were told that the length of the test session was fixed at $20 \mathrm{~min}$ to discourage them from selecting new slides just to get the test over with as quickly as possible. Actually, test sessions ranged from 15 to $20 \mathrm{~min}$ in length, depending upon the number of repetitions requested.

\section{RESULTS}

The mean numbers of slide presentations for the $0.10-, 0.20$-, $1.00-$, and 10.00 -sec stimulus exposure conditions were $1.68,1.44,1.34$, and 1.26 , respectively. The mean numbers of presentations for the $0.00-, 10.00-$, 
20.00-, and 30.00-sec decision delay conditions were $1.37,1.44,1.42$, and 1.48, respectively. Finally, females viewed each slide an average of 1.44 times, while males viewed them 1.42 times. Differences between conditions and their interactions were tested for significance by a 4 by 4 by 2 factorial analysis of variance. All differences and interactions proved to be nonsignificant, except those produced by changes in stimulus duration, $\mathrm{F}(3,32)=6.75, \mathrm{p}<.005$. A Duncan range test, subsequently used to determine which pairs of the four stimulus duration means differed significantly from one another, showed all differences to be significant, except that between the 1.00- and 10.00-sec means.

\section{DISCUSSION}

The hypothesis that the longer $S$ is " exposed to a slide, the less likely he is to request a repetition of that slide was confirmed by the data. This result concurs with similar studies (Cantor \& Cantor, 1964a, 1966; Endsley, 1967) and further supports Glanzer's (1953) statements concerning the development of stimulus satiation. In addition, the data demonstrate for the first time that the hypothesis is generalizable to adults as well as children. This point is significant because it relates to conflicting evidence in the literature. Zajonc (1968) claimed that preference for a stimulus increased with repeated exposures. Cantor \& Kubose (1969) noted that all of Zajonc's Ss were adults, showed that studies employing children produced contradictory results, and suggested that age might be acting as an extraneous variable. The present findings disconfirm this suggestion, showing that adult Ss produced results consistent with Cantor and Kubose's findings for children-longer stimulus exposures were less likely to be repeated.
The finding that all stimulus duration means differed significantly from one another, except the two longest exposures, 1.00 and $10.00 \mathrm{sec}$, points toward the possibility that visual satiation was nearly complete by the time $1.00 \mathrm{sec}$ had elapsed. If this was the case, the time interval needed to produce satiation was briefer than any previously published; nevertheless, it was probably specific to the circumstances of this experiment, and even shorter satiation times may be recorded under different conditions. Future studies may find that the duration necessary to produce satiation varies with (1) the complexity of the stimulus, (2) its affective qualities, (3) age of S, (4) Ss' levels of anxiety, and (5) the particular sensory modality or combination of modalities used by Ss.

The hypothesis that increasing the elapsed time following stimulus exposure increases the likelihood that $S$ will request a reexposure of the preceding stimulus was not confirmed. Though Berlyne (1957) found evidence of recovery from satiation, the present negative finding is in line with the work of Cantor \& Cantor (1964a, b, 1966), who found no evidence of recovery with delay periods considerably longer than those employed here.

Perhaps Berlyne's (1951) discussion of the relation of conditioned $\left(s I_{R}\right)$ and reactive inhibition $\left(I_{R}\right)$ to stimulus events could be used to modify Glanzer's (1953) postulates regarding recovery. According to Berlyne, "Hull's behaviour theory may be extended to the treatment of perception and attention by regarding perception as a stimulus-producing response ('pure stimulus-act') or complex of such responses." The exposure and withdrawal of a stimulus may create $I_{R}$, a temporary fatigue effect, and $S I_{R}$ remains more or less permanently in effect, preventing the stimulus from fully recovering its ability to capture attention. Accordingly, the data collected here display a slight tendency for the stimulus to recover as the delay between the slide exposure and the S's decision increases, but this trend never reaches statistical significance.

\section{REFERENCES}

BERLYNE, D. E. Attention to change. British Journal of Psychology, 1951, 42, 269-278.

BERLYNE, D. E. Attention to change, conditioned inhibition $\left(S^{I}{ }_{R}\right)$ and stimulus satiation. British Journal of Psychology. $1957,48,138-140$.

CANTOR, G. N. Children's "like-dislike" ratings of familiarized and nonfamiliarized visual stimuli. Journal of Experimental Child Psychology, 1968, 6, $651-657$.

CANTOR, J. H., \& CANTOR, G. N Children's observing behavior as related to amount and recency of stimulus familiarization. Journal of Experimental Child Psychology, 1964a, 1, 241-247.

CANTOR, J. H., \& CANTOR, G. N Observing behavior in children as a function of stimulus novelty. Child Development, 1964b, 35, 119-128.

CANTOR, J. H., \& CANTOR, G. N. Functions relating children's observing behavior to amount and recency of stimulus familiarization. Journal of Experimental Psychology, 1966, 72, 859-863.

CANTOR, G. N., \& KUBOSE, S. K. Preschool children's ratings of familiarized and nonfamiliarized visual stimuli. Journal of Experimental Child Psychology, 1969, 8, 74-81.

ENDSLEY, R. C. Effects of differential prior exposure on preschool children's subsequent choice of novel stimuli. Psy chonomic Science, 1967, 7, 411-412.

ENDSLEY, R. C.. \& KESSELL. L. D. Effects of differential prior exposure on kindergarten children's subsequent observing and choice of novel stimuli. Developmental Psychology, 1969, 1 , 193-199

GLANZER, M. Stimulus satiation: An explanation of spontaneous alternation and related phenomena. Psychological Review, 1953, 60, 257-268.

ZAJONC, R. B. Attitudinal effects of mere exposure. Journal of Personality \& Social Psychology Monograph Supplement, 1968, 9(2), 1-27. 